\title{
Clinical perspectives - Biologics in IBD: What's all the fuss?
}

\author{
Hillary Steinhart MD MSc FRCPC
}

\section{H Steinhart. Clinical perspectives - Biologics in IBD: What's} all the fuss? Can J Gastroenterol 2001;15(12):799-804.

Up until the present time, agents with relatively nonspecific anti-inflammatory or immunomodulatory effects such as 5-acetylsalicylic acid, corticosteroids and azathioprine have been the mainstay of inflammatory bowel disease medical therapy. These drugs have been quite useful in one or more clinical settings, but they have been hampered by modest efficacy, significant toxicity or both. With greater understanding of the specific pathways of the gut mucosal immune response, it is hoped that newer biologic response modifiers will provide better efficacy, with an improved adverse event profile compared with older existing therapies. This article examines the evidence behind the use of biologic therapies such as anti-tumour necrosis factor-alpha, interleukin-10, interleukin-11, anti-integrin antibody and antisense intercellular adhesion molecule-1 oligonucleotide

Key Words: Biologics; Inflammatory bowel disease

\section{Perspectives cliniques : Les modificateurs de la réponse biologique dans les MII, et après?}

RÉSUMÉ : Jusqu'à présent, les agents exerçant des effets anti-inflammatoires ou immunomodulateurs relativement non spécifiques, comme l'acide 5-acétylsalicylique, les corticostéroïdes et l'azathioprine, ont formé la base du traitement médical des maladies inflammatoires de l'intestin. Ces médicaments se sont révélés utiles dans plus d'un contexte clinique, mais ils sont d'une efficacité modeste et provoquent parfois des réactions secondaires importantes. Compte tenu de l'approfondissement des connaissances sur les voies spécifiques de la réponse immunitaire au niveau de l'intestin, il est à espérer que les prochains modificateurs de la réponse biologique seront plus efficaces et mieux tolérés que les thérapeutiques existantes. Cet article se penche sur les résultats obtenus avec des agents biologiques, tels les anti-facteurs alpha de la nécrose tumorale, l'interleukine-10, l'interleukine-11, l'anticorps anti-intégrine et l'oligonucléotide antisens de la molécule-1 de l'adhésion intercellulaire.
U nderstanding of the underlying pathogenesis of the nonspecific inflammatory bowel diseases (IBD), Crohn's disease (CD) and ulcerative colitis (UC), has evolved gradually. Theories about its causation have been promoted, only to be disproven or at least shown to be unlikely given the weight of the evidence. The current, most widely held view is that IBD is the result of certain environmental expo- sures in genetically susceptible individuals. This interplay between gene and environment likely results in the perturbation of the normal state of 'controlled inflammation' that is present in the gut mucosa and submucosa. This, in turn, results in the excessive or uncontrolled inflammation that is recognized clinically as UC and CD. This uncontrolled inflammation and a patient's susceptibility to it have been

Department of Medicine, University of Toronto, Division of Gastroenterology, Mount Sinai Hospital, Toronto, Ontario

Correspondence and reprints: Dr A Hillary Steinhart, Room 445, Mount Sinai Hospital, 600 University Avenue, Toronto, Ontario M5G 1 X5.

Telephone 416-586-5121, fax 416-586-3174, e-mail hsteinhart@mtsinai.on.ca

Received for publication March 27, 2000. Accepted June 23, 2000 

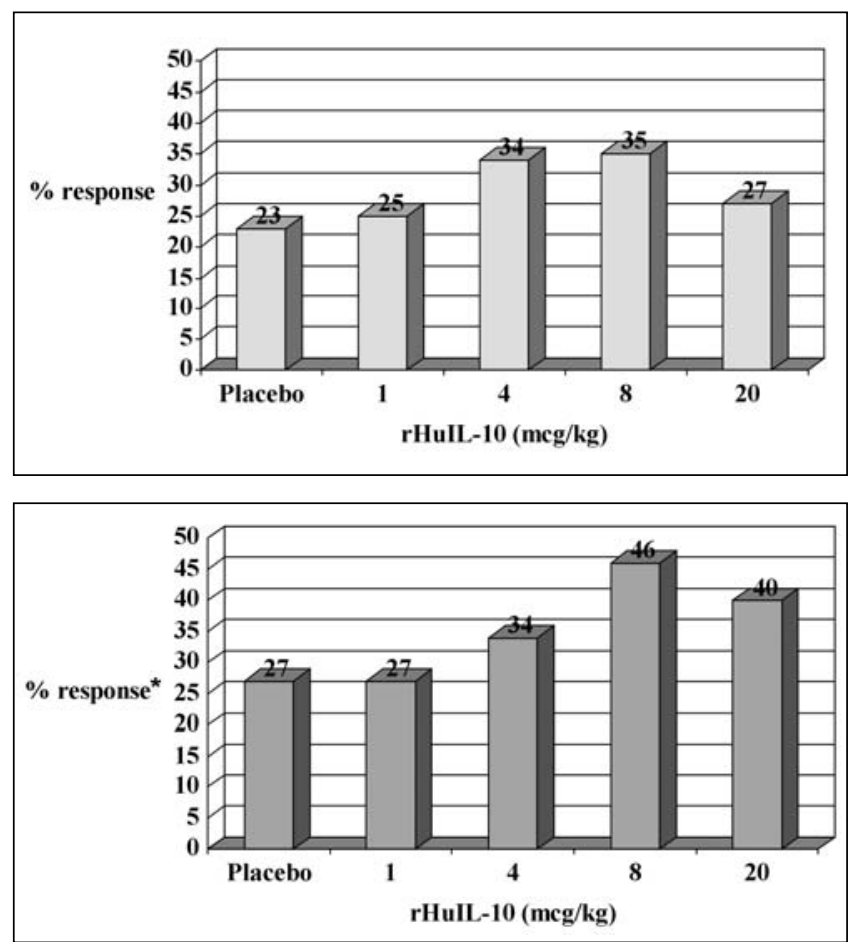

Figure 1) Top Proportion of patients responding to placebo or recombinant human interleukin-10 (rHuIL-10). Response is defined as a reduction in the Crohn's Disease Activity Index (CDAI) of 70 or more points. Bottom The CDAI scores after treatment have been adjusted to account for the reduction in hematocrit consistently observed in patients receiving higher doses of $r \mathrm{HuIL}-10$. *Response based on hematocrit-corrected CDAI

the attention of much of the research into drug development and therapeutic strategies for IBD. Until the present time, agents with relatively nonspecific anti-inflammatory or immunomodulatory effects have been the mainstay of IBD medical therapy. Examples of such drugs include corticosteroids, sulphasalazine, mesalamine, azathioprine, 6-mercaptopurine and cyclosporine. Each of these drugs has been useful in one or more clinical settings in IBD, but they have also been hampered by modest efficacy, significant toxicity or both in many of the settings in which they have been used. Clearly, newer drug therapies for patients suffering from IBD need to be developed.

With greater understanding of the specific pathways of the gut mucosal immune response and the pathogenesis of gastrointestinal tract inflammation, it has been hoped that newer 'biologic' drugs will provide better efficacy, with an improved adverse event profile compared with that of older existing therapies. This hope is based on the presumption that the identification of key mediators or pathways in the abnormal immune response will permit the development of complex biologic molecules that will somehow block, modify or enhance these specific key aspects of the immune response. A corollary of this expectation is that, by modifying only the abnormal aspects of the immune response and leaving the other more physiological or appropriate aspects unchanged, the adverse consequences that are frequently seen with the use of nonspecific immunosuppressive or immunomodulatory drugs can be avoided.

$\mathrm{CD}$ and UC appear to have two somewhat different immunological profiles, with CD having primarily a $\mathrm{T}$ helper cell 1 type response and UC having primarily a $\mathrm{T}$ helper cell 2 type response (1-6). Specific cytokine patterns associated with each of these response types are, therefore, thought to distinguish CD from UC. CD is characterized by increased levels of tumour necrosis factor (TNF)- $\alpha$, interleukin (IL)-1 $\beta$, IL-2 and interferon gamma in intestinal tissue, whereas elevated levels of IL-4 and IL10 are observed in patients with UC. If one or more of these cytokines play a pivotal role in the propagation of the inappropriate inflammatory response seen in $\mathrm{CD}$ and $\mathrm{UC}$ it should provide an obvious target for immunomodulatory or biologic response modifier therapy. There are currently several 'biologic' therapies under development, undergoing clinical trial evaluation or awaiting regulatory approval for use in the treatment of IBD in Canada. The present article examines the evidence behind the use of these biologic therapies and attempts to determine whether they have fulfilled their promise and whether they are likely to do so in the future.

\section{IL-10}

IL-10 is a cytokine that is produced and secreted by T cells. Mice that are rendered deficient in IL-10 by gene knockout techniques develop a chronic enterocolitis resembling, in some respects, chronic IBD in humans (7). IL-10 is thought to have a downregulatory effect on the mucosal immune response and has, therefore, been proposed to be a potential therapy for IBD $(6,8)$. The therapeutic use of recombinant human IL-10 (rHuIL-10) was originally reported by van Deventer and colleagues (9) in 46 patients with active, steroid-resistant CD. In that placebo controlled, dose ranging study, IL-10 was administered as daily intravenous infusions for seven days, and was found to be safe and produce some degree of clinical benefit, with a slight reduction in the Crohn's Disease Activity Index (CDAI) in the patients treated with IL-10. In addition, approximately $50 \%$ of the patients treated with IL-10 were in remission at some point in the three-week follow-up phase compared with $23 \%$ of the placebo-treated patients (9). Pharmacokinetic studies have indicated that rHuIL-10 is well absorbed when given as a subcutaneous injection, and subsequent trials of rHuIL-10 have used this route of drug administration, usually by the patients themselves, to test the drug's safety and efficacy. A large placebo controlled, dose-finding study of subcutaneous rHuIL-10 given once daily for 28 days in 329 patients with chronically active, steroid-resistant $\mathrm{CD}$ revealed only a minimal clinical benefit compared with that of placebo (Figure 1, top). The primary predetermined analysis of the proportion of patients in remission in the various dose levels revealed no significant difference between the drug and placebo. However, a reanalysis of the data, adjusting for the known negative effect of higher doses 
of rHuIL-10 on hematocrit, showed a slight advantage for the $8 \mu \mathrm{g} / \mathrm{kg}$ dose compared with placebo (10) (Figure 1, bottom). Interestingly, a lower response rate was noted at the higher $20 \mu \mathrm{g} / \mathrm{kg}$ dose level than at the $8 \mu \mathrm{g} / \mathrm{kg}$ dose level, although the difference was not statistically significant. This type of biphasic dose-response curve appears to be a common finding in studies of biologic therapies and suggests that, with many cytokines or immunomodulatory molecules, there may be a relatively small therapeutic window that, if missed, could result in negative study results.

Another study of rHulL-10 was carried out in 94 patients with mild to moderately active UC (11). The study employed four different doses of rHuIL-10 or placebo, which were administered subcutaneously every day for 28 days. Although the stated purpose of the study was to study the safety and tolerance of $\mathrm{rHu} 1 \mathrm{~L}-10$, there was a trend toward a better percentage reduction in the UC symptom score in the group that received the three higher doses than in the group that received the placebo. However, there was no increase in the proportion of patients achieving clinical remission at the end of treatment.

Subcutaneous IL-10 was well tolerated by patients when administered daily for 28 days. The most common side effects were influenza-like symptoms that were generally mild and easily managed with acetaminophen, and a reduction in the platelet count. The reduction in platelet count was seen primarily at the higher dose levels, and platelet counts usually did not fall to a level below the lower limit of normal. However, when thrombocytopenia was observed, it was quickly reversed by discontinuation of the drug, and no serious bleeding occurred as a result of therapy.

The relatively modest efficacy observed in the large rHuIL-10 CD trial was likely related to at least two factors. First, the study enrolled only patients with chronically active, steroid-resistant $\mathrm{CD}$ who had been experiencing symptoms for many months at the time of randomization. These patients were, therefore, less likely to respond to any form of medical therapy than patients with treatment-naive disease. Second, IL-10 likely acts on a relatively distal or downstream arm of the mucosal immune response. As a result, the redundancy in the immune response likely allows other pathways that are not blocked or modified by IL-10 to adjust their activity such that the same level of mucosal inflammation is maintained. For IL-10 to produce a clinically meaningful benefit, it would likely have to be used in patients with less refractory or less advanced disease. A study to determine the efficacy of rHuIL-10 in patients with inactive but steroid-dependent disease is in progress.

\section{IL-11}

IL-11 is a cytokine that is produced by mesenchymal cells in many tissues of the body. IL-11 has been shown to result in increased platelet production and has also been found to have protective effects in models of intestinal injury. The recombinant human form (rhIL-11) is used to treat chemotherapy-induced thrombocytopenia in patients with malignancies. In animal models of IBD, IL-11 reduces measures of intestinal inflammation and is, therefore, under investigation for the treatment of CD in humans. Sands et al (12) reported the results of a multicentre, randomized, double-blind, placebo controlled, dose-escalation study of rhIL-11 in 76 patients with active CD. The active drug was administered via the subcutaneous route in two different schedules - either two or five doses per week at one of three different total weekly doses of 5, 16 and $40 \mu \mathrm{g} / \mathrm{kg} /$ week - for three weeks. Other medications, such as mesalazine, sulphasalazine and oral corticosteroids (equivalent to prednisone $20 \mathrm{mg} /$ day or less) were permitted at a stable dose through the study period.

Using fairly standard definitions of response and remission, clinical response was observed in nine of 24 patients, and remission was observed in six of 24 patients receiving the $16 \mu \mathrm{g} / \mathrm{kg} /$ week dose compared with one of 15 and none of 15 placebo-treated patients experiencing response and remission, respectively. Interestingly, a linear dose-response relationship was not observed. There did, however, appear to be a biphasic dose-response curve, with a lower rate of response and remission in the groups that received 5 and $40 \mu \mathrm{g} / \mathrm{kg} /$ week compared with the group that received $16 \mu \mathrm{g} / \mathrm{kg} /$ week.

The safety of rhIL-11 in the treatment of CD has been a concern given its known stimulatory effect on platelet production and the known thrombotic tendency of these patients. Although greater increases in platelet counts were seen at the higher dose levels and with the five times per week administration schedule, the increases were transient and resolved after discontinuation of therapy. No thrombotic events were observed during the three-week treatment period or during the four-week follow-up period. Similar increases in the acute phase reactants, fibrinogen and C-reactive protein, were seen with the higher doses and more frequent dosing schedules, but these increases were not associated with any apparent increase in symptoms due to gut inflammation. The most common adverse event was injection site reaction.

Further studies involving larger numbers of patients with varying disease sites and manifestations are required to confirm the efficacy of rhIL-11, to determine the optimal dose and duration of therapy, and to determine the most appropriate indications for its use.

\section{ANTI-TNF ANTIBODY}

One molecule that is thought to be central in the inflammatory response of CD is TNF- $\alpha$. This protein is secreted by macrophages in response to antigen presentation and, in turn, can upregulate many proinflammatory cytokines. TNF- $\alpha$, therefore, is an attractive therapeutic target, and several strategies have been developed to block its activity. These strategies include a chimeric mouse/human antiTNF- $\alpha$ antibody (infliximab), a humanized monoclonal anti-TNF $\alpha$ antibody (CDP 571) and a soluble TNF- $\alpha$ receptor/Fc fusion protein (etanercept).

The chimeric mouse-human anti-TNF- $\alpha$ antibody, infliximab, has been the most widely studied and used of 
the biologic agents and, to date, shows the greatest promise. Its activity has been thought to be secondary to its ability to bind both circulating and membrane-bound TNF- $\alpha$, possibly through complement fixation and lysis of cells expressing TNF- $\alpha$ (13). Targan et al (14) studied the use of infliximab in patients with chronically active $\mathrm{CD}$, and, when given as a single intravenous infusion of 5,10 or $20 \mathrm{mg} / \mathrm{kg}$, it was found to induce remission in approximately $33 \%$ of patients at four weeks. The highest response rate was observed in the group that received $5 \mathrm{mg} / \mathrm{kg}$ ( 22 of 27 patients; $81 \%$ ). In that study, approximately $60 \%$ of patients had been receiving corticosteroids and $37 \%$ had been receiving azathioprine or 6-mercaptopurine for a minimum of eight weeks at the time of randomization; these patients presumably would be considered treatment refractory because all patients had active disease at baseline, with a mean CDAI of between 288 and 318. For patients who responded to one or two initial infusions, repeated infusions of $10 \mathrm{mg} / \mathrm{kg}$ given every eight weeks appeared to maintain the initial improvement better than placebo. It is not clear how many patients were receiving corticosteroids upon entry into the chronic retreatment study or whether there was any observed steroid-sparing effect over the course of 48 weeks (15). Given the relatively small number of patients in the study (infliximab 37, placebo 36) and the lack of a well-defined, standard protocol for steroid tapering, it is unlikely that a significant steroid-sparing effect would have been detected. When decisions need to be made regarding the use of infliximab in patients with $\mathrm{CD}$, consideration should be given to the fact that repeated infusions can be very costly and may be associated with an increased risk of adverse reactions such as infusion reactions and the development of human antichimeric antibodies. The development of these antibodies may be associated with infusion reactions and may preclude further use of infliximab. The appropriate place for infliximab in the treatment of CD will ultimately depend on its long term efficacy and ability to prevent disease complications. To achieve that effect, combination therapy with an immunosuppressive drug such as methotrexate or a purine analogue may be required.

Another strategy to block the effects of TNF- $\alpha$ is the intravenous infusion of another form of antibody, CDP571, which is a humanized monoclonal antibody. Unlike infliximab, CDP571 is thought not to bind complement or result in complement-mediated cytotoxicity (13). In an initial small study, a single $5 \mathrm{mg} / \mathrm{kg}$ intravenous infusion of CDP571 resulted in a reduction in the median CDAI of 20 patients from 263 to 167 by two weeks after the infusion. No change in CDAI was seen in the 10 placebo-treated patients (16). Subsequent large trials of CDP571 have been completed, and preliminary analysis of the results suggests that CDP571, when given as an initial infusion of $10 \mathrm{mg} / \mathrm{kg}$, is effective in improving disease activity in patients with treatment-refractory $\mathrm{CD}$. In addition, it appears that an initial infusion of $20 \mathrm{mg} / \mathrm{kg}$ followed eight weeks later by a second infusion of $10 \mathrm{mg} / \mathrm{kg}$ maintains remission and permits tapering of corticosteroids in patients with steroid-dependent CD.

Two small studies, one using infliximab and one using CDP 571, have been carried out in patients with severely active and mildly to moderately active ulcerative colitis, respectively $(17,18)$. These studies appear to show some evidence of anti-inflammatory activity associated with the use of anti-TNF $\alpha$ strategies in UC, but the studies were either uncontrolled or too small to draw any final conclusions.

The consistency of the clinical response observed in the various trials of different anti-TNF antibodies in CD indicates that this treatment strategy is of benefit and supports the hypothesis that TNF- $\alpha$ is an important mediator of the uncontrolled inflammation observed in patients with CD. Although the short term efficacy and safety of anti-TNF antibodies appear to be very good, there are much fewer data regarding their long term efficacy and safety. It has been shown that repeated infusions of infliximab, given every eight weeks for up to 40 weeks, maintains clinical improvement and remission in patients responding to an initial infusion of infliximab (15). However, the optimal dose, dosing schedule and use of concomitant medications are not yet known, and issues of long term safety need to be determined before the place of anti-TNF strategies are well established in the treatment of patients with CD.

\section{ANTI-ADHESION MOLECULE STRATEGIES}

Adhesion molecules and their ligands that are present on the surfaces of inflammatory or immunocompetent cells, vascular endothelial cells and gut epithelial cells are important in the recruitment and retention of these inflammatory and immunocompetent cells into sites of tissue damage or antigen stimulation (19-21). Expression of many of these molecules has been shown to be increased in the inflamed intestinal mucosa of patients with CD and UC (22-25). It has been suggested that IBD could be effectively treated by blocking the activity of these adhesion molecules or that of their ligands. At least two means of interfering with the action of adhesion molecules, such as the intercellular adhesion molecules (ICAMs) or their ligands such as integrins that are present on inflammatory cells, have been developed and tested in animal models of IBD and, in some cases, in human disease. These methods are the use of blocking antibodies against those adhesion molecules and ligands that are thought to be important in inflammatory cell recruitment $(19,26-31)$, and the infusion of antisense oligonucleotides against the mRNA of adhesion molecules (32-34).

Most of the data regarding antiadhesion molecule strategies pertain to animal studies, but the results of ongoing and planned human clinical trials of several antiadhesion molecule therapies should provide more information regarding the safety and efficacy of these molecules in humans.

A small randomized, placebo controlled trial of antisense oligonucleotide against ICAM-1 provided encourag- 
ing results (34). In that trial, patients with chronically active, steroid-treated $\mathrm{CD}$ were randomly assigned to receive either placebo infusions or infusions of one of three doses of the antisense oligonucleotide against ICAM-1 (ISIS 2302). Thirteen infusions were given over 26 days, and patients were evaluated for clinical response at the end of treatment and followed for up to six months. Remission was observed in seven of 15 (47\%) of the ISIS 2302-treated patients. One of the five placebo-treated (20\%) patients achieved clinical remission at the end of treatment. Five of the seven responders had sustained response over six months. The treatment appeared to be well tolerated. Despite the initial enthusiasm, a large randomized, controlled trial of ISIS 2302 in 300 patients with chronically active CD showed no clinical benefit (35).

Another adhesion molecule that has been shown to have increased expression in IBD is the integrin alpha beta $_{7}$ (36). Monoclonal antibodies against alpha beta $_{7}$ or its individual components has been shown to be effective in the cotton-top tamarin model of UC $(29,31)$. Other investigators studied the use of antibodies directed against both mucosal addressin cell adhesion molecule-1, an adhesion molecule found on endothelial cells in the gut, and its ligand, the beta ${ }_{7}$ integrin, in a severe combined immunodeficient mouse model of colitis (30). Both of these antibodies reduced the influx of lymphocytes into the colon and resulted in reduced histological parameters of inflammation.

Although the animal antibody studies have been very encouraging, extensive human studies have not yet been reported. The antibody against the alpha $b_{4} \mathrm{beta}_{7}$ integrin molecule has undergone early clinical testing in human $\mathrm{UC}$, but it is too soon to determine whether this strategy will be effective.

\section{ROLE OF BIOLOGICS IN IBD THERAPY}

The use of biologic response modifiers in the treatment of $\mathrm{CD}$ and $\mathrm{UC}$ is in its infancy. These new therapeutic agents will ultimately be judged based on their efficacy, safety and cost relative to other existing and accepted treatments for IBD. In particular, they will likely be compared with the glucocorticoids, immunomodulators (azathioprine, 6-mercaptopurine, methotrexate and cyclosporine) and surgery. Until direct comparative trials are performed, any conclusions regarding the relative efficacy of therapeutic strategies will remain inferred and indirect. However, in the absence of such comparative studies, physicians and patients must still make decisions about whether to use a biologic therapy, the place of biologic therapies in the overall management plan, whether to use the biologic therapy alone as monotherapy or in combination with other therapeutic agents, and how long to use a biologic therapy. The only biologic response modifiers that have clearly been shown to have a beneficial therapeutic effect are the anti-TNF- $\alpha$ antibodies, infliximab and CDP571, when used in the treatment of CD. Because of the relative inaccessibility of these drugs in Canada, their relatively high cost and the questions regarding long term efficacy and safety, the use of
anti-TNF- $\alpha$ antibodies should probably not be considered 'first-line' therapy for most patients with $\mathrm{CD}$. The exception may be the patient with external fistulae secondary to CD. In this clinical scenario, infliximab is the only drug that has been proven to have a beneficial effect in terms of reduction of drainage and closure of fistulae. Even so, the durability of the response is not entirely known, and it is likely that patients who respond will require ongoing infliximab therapy or concomitant therapy with other agents such as azathioprine or antibiotics to maintain the improvement. Anti-TNF- $\alpha$ antibody should probably be considered 'second-line' therapy for patients with chronically active $\mathrm{CD}$ who are not responding to glucocorticoids or immunomodulatory therapy or who are intolerant of these medications and for patients with steroid-dependent disease who have failed to respond to other steroid-sparing strategies. As further data regarding the use of infliximab and CDP 571 accumulate, these suggestions may change, particularly if the use of anti-TNF- $\alpha$ antibodies is found to affect the natural history of the disease. In patients with rheumatoid arthritis, the use of infliximab has been demonstrated to slow or reduce the radiographic evidence of joint damage. In patients with $\mathrm{CD}$, if similar effects on scarring, ulceration and fistulization could be achieved, the use of infliximab could be considered early on in the course of the disease, even before the use of glucocorticoids or immunomodulatory agents.

Firm conclusions about many of the other biologic agents cannot be made because of the relatively small amount of data available regarding their efficacy and safety. The agents about which conclusions cannot be drawn include rhIL-11 and the anti-integrin antibodies. It does appear, however, that the antisense oligonucleotide to ICAM-1 (ISIS 2302) is unlikely to have an important role in the treatment of CD. In addition, rHuIL-10, although apparently quite safe, has been shown to have only modest efficacy and will likely be useful in only certain selected situations, if at all. These situations might include the prevention of postoperative recurrence of $\mathrm{CD}$ or the maintenance of remission in patients with CD or UC.

The biologic agents are certain to be very expensive relative to existing medical therapies, and their use will almost certainly increase the total drug expenditures for patients with IBD. Whether this increased cost is offset by improvements in clinical status and quality of life or by reductions in other expenditures remains to be determined. The largest portion of the cost of caring for patients with $\mathrm{CD}$ is due to hospitalization (37). Therefore, it could be argued that the increased drug costs associated with the use of new biologic therapies might be offset by reducing the need for hospitalization, even with the use of newer, more expensive medications. The recommendation to treat a patient with a biologic response modifier should be based on the efficacy and safety of the agent and its likelihood of producing a measurable and important benefit for the patient. Issues of payment and compensation will ultimately be considered by governments, insurance companies and patients. 


\section{REFERENCES}

1. Plevy SE, Landers CJ, Prehn J, et al. A role for TNF-alpha and mucosal T helper-1 cytokines in the pathogenesis of Crohn's disease. J Immunol 1997;159:6276-82.

2. Breese EJ, Michie CA, Nicholls SW, et al. Tumor necrosis factor alpha-producing cells in the intestinal mucosa of children with inflammatory bowel disease. Gastroenterology 1994;106:1455-66.

3. Dionne S, Hiscott J, D'Agata I, Duhaime A, Seidman EG. Quantitative PCR analysis of TNF-alpha and IL-1 beta mRNA levels in pediatric IBD mucosal biopsies. Dig Dis Sci 1997;42:1557-66.

4. MacDonald TT, Hutchings P, Choy MY, Murch S, Cooke A. Tumour necrosis factor-alpha and interferon-gamma production measured at the single cell level in normal and inflamed human intestine. Clin Exp Immunol 1990;81:301-5.

5. Nielsen OH, Koppen T, Rudiger N, Horn T, Eriksen J, Kirman I. Involvement of interleukin-4 and -10 in inflammatory bowel disease. Dig Dis Sci 1996;41:1786-93.

6. Niessner M, Volk BA. Altered Th1/Th2 cytokine profiles in the intestinal mucosa of patients with inflammatory bowel disease as assessed by quantitative reversed transcribed polymerase chain reaction (RT-PCR). Clin Exp Immunol 1995;101:428-35.

7. Kuhn R, Lohler J, Rennick D, Rajewsky K, Muller W. Interleukin-10-deficient mice develop chronic enterocolitis. Cell 1993;75:263-74.

8. Schreiber S, Heinig T, Thiele HG, Raedler A. Immunoregulatory role of interleukin 10 in patients with inflammatory bowel disease. Gastroenterology 1995;108:1434-44.

9. van Deventer SJ, Elson CO, Fedorak RN. Multiple doses of intravenous interleukin 10 in steroid-refractory Crohn's disease. Crohn's Disease Study Group. Gastroenterology 1997;113:383-9.

10. Schreiber S, Fedorak RN, Nielsen $\mathrm{OH}$, et al. A safety and efficacy study of recombinant human interleukin-10 (rHuIL-10) treatment in 329 patients with chronic active Crohn's disease. Gastroenterology 1998;114:A1080. (Abst)

11. Schreiber S, Fedorak RN, Wild G, et al. Safety and tolerance of rHuIL-10 treatment in patients with mild/moderate active ulcerative colitis. Gastroenterology 1998;114:A1080-1.

12. Sands BE, Bank S, Sninsky CA, et al. Preliminary evaluation of safety and activity of recombinant human interleukin 11 in patients with active Crohn's disease. Gastroenterology 1999;117:58-64.

13. Sandborn WJ, Hanauer SB. Antitumor necrosis factor therapy for inflammatory bowel disease: a review of agents, pharmacology, clinical results, and safety. Inflamm Bowel Dis 1999;5:119-33.

14. Targan SR, Hanauer SB, van Deventer SJ, et al. A short-term study of chimeric monoclonal antibody cA2 to tumor necrosis factor alpha for Crohn's disease. Crohn's Disease cA2 Study Group. N Engl J Med 1997;337:1029-35.

15. Rutgeerts P, D'Haens G, Targan S, et al. Efficacy and safety of retreatment with anti-tumor necrosis factor antibody (infliximab) to maintain remission in Crohn's disease. Gastroenterology 1999;117:761-9.

16. Stack WA, Mann SD, Roy AJ, et al. Randomised controlled trial of CDP571 antibody to tumour necrosis factor-alpha in Crohn's disease . Lancet 1997;349:521-4.

17. Evans RC, Clarke L, Heath P, Stephens S, Morris AI, Rhodes JM. Treatment of ulcerative colitis with an engineered human anti-TNF-alpha antibody CDP571. Aliment Pharmacol Ther 1997;11:1031-5.

18. Sands BE, Podolsky DK, Tremaine WJ, et al. Chimeric monoclonal anti-tumor necrosis factor antibody (cA2) in the treatment of severe, steroid-refractory ulcerative colitis (UC). Gastroenterology 1996;110:A1008. (Abst)

19. Ludviksson BR, Strober W, Nishikomori R, Hasan SK, Ehrhardt RO. Administration of $\mathrm{mAb}$ against alpha $\mathrm{E}$ beta 7 prevents and ameliorates immunization-induced colitis in IL-2-/- mice. J Immunol 1999;162:4975-82.
20. Sans M, Panes J, Ardite E, et al. VCAM-1 and ICAM-1 mediate leukocyte-endothelial cell adhesion in rat experimental colitis. Gastroenterology 1999;116:874-83.

21. Parkos CA, Colgan SP, Diamond MS, et al. Expression and polarization of intercellular adhesion molecule-1 on human intestinal epithelia: consequences for CD11b/CD18-mediated interactions with neutrophils. Mol Med 1996;2:489-505.

22. Lazaris AC, Dicoglou C, Tseleni-Balafouta S, Paraskevakou H, Davaris PS. In situ expression of E-selectin and intercellular adhesion molecule-1 in chronic inflammatory diseases of the gastrointestinal tract. APMIS 1999; 107:819-27.

23. Bernstein CN, Sargent M, Gallatin WM. Beta ${ }_{2}$ integrin/ICAM expression in Crohn's disease. Clin Immunol Immunopathol 1998;86:147-60.

24. Cellier C, Patey N, Fromont-Hankard G, et al. In-situ endothelial cell adhesion molecule expression in ulcerative colitis. E-selectin in-situ expression correlates with clinical, endoscopic and histological activity and outcome. Eur J Gastroenterol Hepatol 1997;9:1197-203.

25. Nielsen $\mathrm{OH}$, Brynskov J, Vainer B. Increased mucosal concentrations of soluble intercellular adhesion molecule-1 (sICAM-1), sE-selectin, and interleukin-8 in active ulcerative colitis. Dig Dis Sci 1996;41:1780-5.

26. Taniguchi T, Tsukada H, Nakamura H, et al. Effects of the antiICAM-1 monoclonal antibody on dextran sodium sulphate-induced colitis in rats. J Gastroenterol Hepatol 1998;13:945-9.

27. Hamamoto N, Maemura K, Hirata I, Murano M, Sasaki S, Katsu K. Inhibition of dextran sulphate sodium (DSS)-induced colitis in mice by intracolonically administered antibodies against adhesion molecules (endothelial leucocyte adhesion molecule-1 (ELAM-1) or intercellular adhesion molecule-1 (ICAM-1)). Clin Exp Immunol 1999; 117:462-8.

28. Wong PY, Yue G, Yin K, et al. Antibodies to intercellular adhesion molecule-1 ameliorate the inflammatory response in acetic acidinduced inflammatory bowel disease. J Pharmacol Exp Ther 1995;274:475-80.

29. Hesterberg PE, Winsor-Hines D, Briskin MJ, et al. Rapid resolution of chronic colitis in the cotton-top tamarin with an antibody to a guthoming integrin alpha 4 beta 7. Gastroenterology 1996;111:1373-80.

30. Picarella D, Hurlbut P, Rottman J, Shi X, Butcher E, Ringler DJ. Monoclonal antibodies specific for beta 7 integrin and mucosal addressin cell adhesion molecule-1 (MAdCAM-1) reduce inflammation in the colon of scid mice reconstituted with CD45RBhigh CD4+ T cells. J Immunol 1997;158:2099-106.

31. Podolsky DK, Lobb R, King N, et al. Attenuation of colitis in the cotton-top tamarin by anti-alpha 4 integrin monoclonal antibody. J Clin Invest 1993;92:372-80.

32. Bennett CF, Kornbrust D, Henry S, et al. An ICAM-1 antisense oligonucleotide prevents and reverses dextran sulfate sodium-induced colitis in mice. J Pharmacol Exp Ther 1997;280:988-1000.

33. Chiang MY, Chan H, Zounes MA, Freier SM, Lima WF, Bennett CF. Antisense oligonucleotides inhibit intercellular adhesion molecule 1 expression by two distinct mechanisms. J Biol Chem 1991;266:18162-71.

34. Yacyshyn BR, Bowen-Yacyshyn MB, Jewell L, et al. A placebocontrolled trial of ICAM-1 antisense oligonucleotide in the treatment of Crohn's disease. Gastroenterology 1998;114:1133-42.

35. Isis Announces Disappointing Results from ISIS 2302 Clinical Trial in Crohn's Disease. Carlsbad: Isis Pharmaceuticals Inc, 1999.

36. Souza HS, Elia CC, Spencer J, MacDonald TT. Expression of lymphocyte-endothelial receptor-ligand pairs, alpha $_{4}$ beta $_{7} /$ MAdCAM-1 and OX40/OX40 ligand in the colon and jejunum of patients with inflammatory bowel disease. Gut 1999;45:856-63.

37. Feagan BG, Larson LR, Vreeland MG, Bala MV. Annual cost of care for Crohn's disease. Gastroenterology 1999;116:A57. (Abst) 


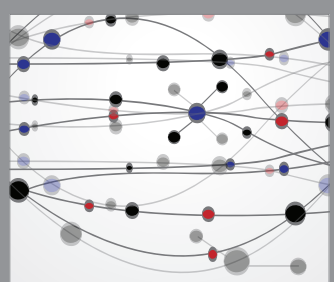

The Scientific World Journal
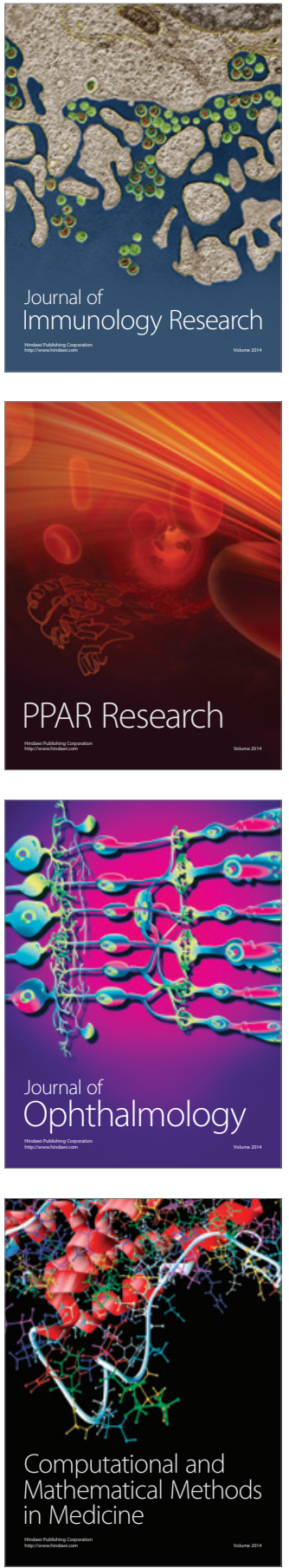

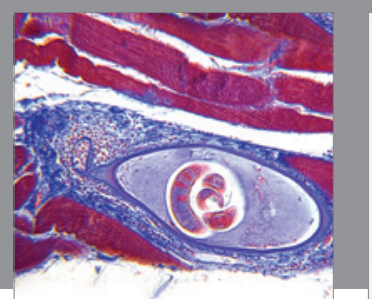

Gastroenterology Research and Practice

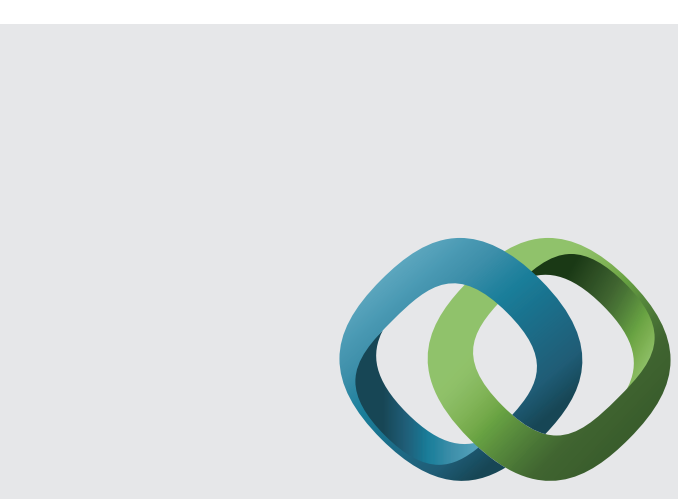

\section{Hindawi}

Submit your manuscripts at

http://www.hindawi.com
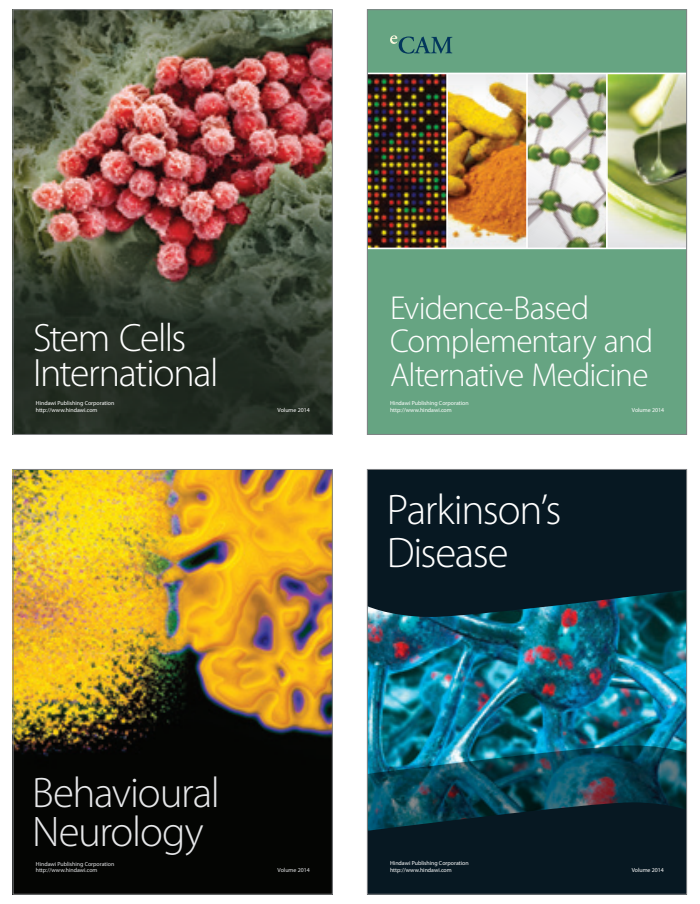
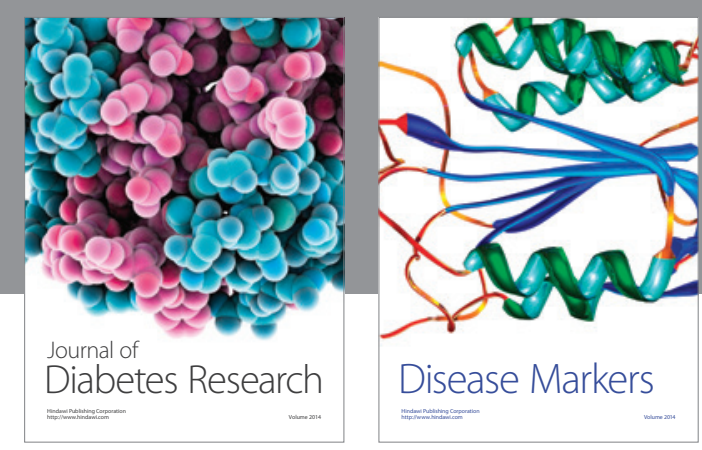

Disease Markers
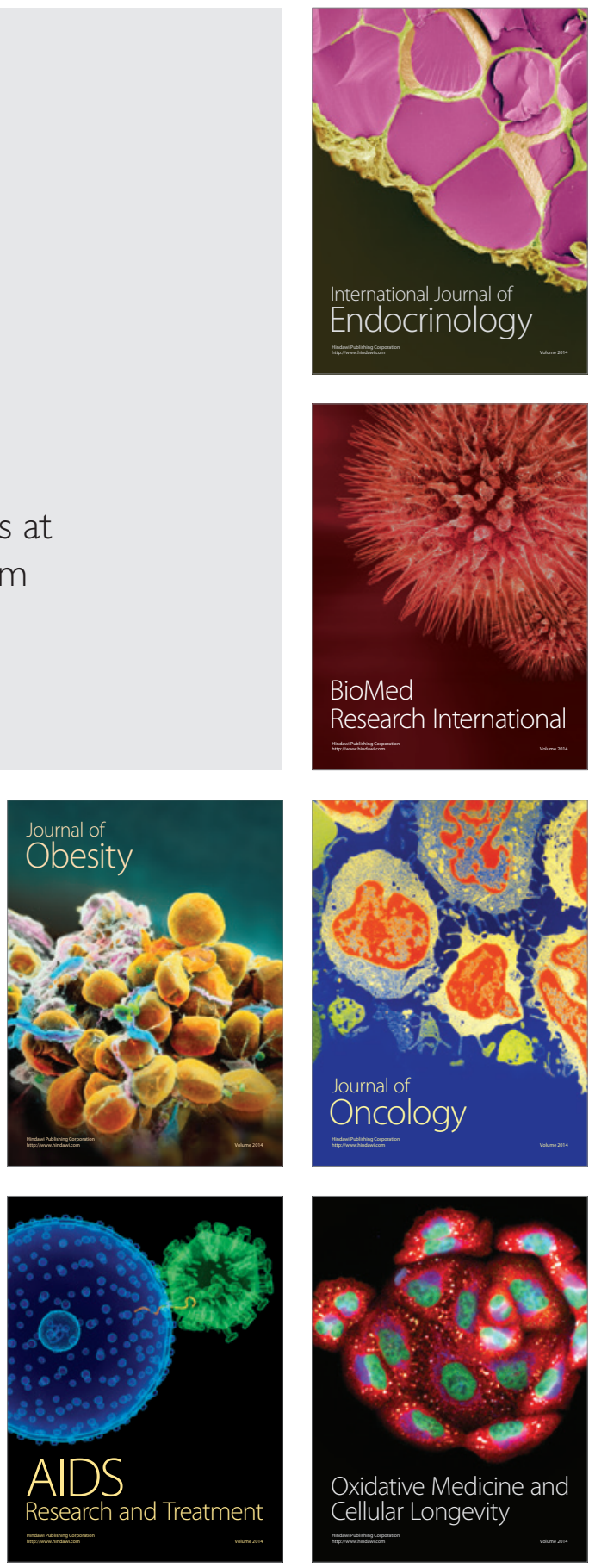